\title{
Carnaval como instrumento de inclusão social de pessoas com deficiência
}

\section{Carnivalas a tool of social inclusion of people with disabilities}

\section{Carnaval como una herramienta de inclusión social de las personas con discapacidad}

\section{J ussélio Rodrigues Ribeiro}

Universidade Salgado de Oliveira - UNIVERSO, Niterói, Rio de Janeiro, RJ, Brasil

\section{Luciana Mourão}

Universidade Salgado de Oliveira - UNIVERSO, Niterói, Rio de Janeiro, RJ, Brasil

\begin{abstract}
RESUMO
A inclusão social vem sendo mais discutida na sociedade e a literatura PSI aponta crescente atuação das empresas em programas voltados a essa temática. O objetivo deste estudo foi avaliar o Projeto Embaixadores da Alegria, que usa o Carnaval como instrumento de inclusão social. A pesquisa multimétodo (pesquisa documental, questionário e entrevistas) contemplou 538 pessoas, incluindo beneficiários, familiares, membros da comunidade, gestores, financiadores e executores do Projeto. O delineamento foi de um quase-experimento que verificou se a participação no programa aumentava a percepção de inclusão social. Os resultados do teste permitem concluir que o Projeto atende apenas parcialmente aos seus objetivos, pois não houve diferenças significativas em relação à favorabilidade à inclusão escolar entre grupo de tratamento e grupo controle. De forma complementar, na análise de conteúdo, foram identificadas cinco categorias relacionadas a aspectos processuais e de resultados do projeto, a saber: (i) participação da família; (ii) formas de comunicação; (iii) mobilidade; (iv) trabalho e geração de renda; e ( $v$ ) inclusão social. Os achados da pesquisa foram debatidos a partir do referencial teórico. São feitas recomendações para o Projeto e sugestões de novos estudos.
\end{abstract}

Palavras-chaves: Carnaval, deficientes, inclusão, programas.

\begin{abstract}
Social inclusion has been more discussed in society. The literature points increasing role of companies in facing this social inclusion programs. The aim of this study was to evaluate the Project Ambassadors of Joy (Projetos Embaixadores da Alegria), which uses the carnival as a tool for social inclusion. The multimethod research (document analysis, questionnaires and interviews) included 538 people (beneficiaries, family members, community members, administrators, funders and implementers of the project). The design was a quasi-experiment that examined whether participation in the program increased awareness of social inclusion. The results of the test demonstrated that the project achieved its objectives only partially because
\end{abstract}


there was no significant difference in relation to favorability to school inclusion between treatment group and control group. As a complement, in the content analysis, we identified five categories related to procedural aspects and results of the project, namely: (i) family participation; (ii) forms of communication; (iii) mobility; (iv) employment and income generation; and (v) social inclusion. The findings of the research were discussed from the theoretical framework. We give recommendations for the project and suggestions for further research.

Keywords: Carnival, disabled, inclusion, programs.

\section{RESUMEN}

La inclusión social ha sido más discutida en la sociedad. La literatura en esta área muestra el aumento de la participación de las empresas para afrontar los retos de este tema. Este estudio objetivó evaluar el Proyecto Embajadores de la Alegría (Projeto Embaixadores da Alegria), el cual usa el carnaval como instrumento de inclusión social. Una investigación multimétodo (análisis documental, cuestionarios y entrevistas) incluyó 538 personas, entre los beneficiarios, los miembros de la familia, miembros de la comunidad, administradores, financieros y ejecutores de proyectos. El diseño era un casi un experimento para probar si la participación en el programa aumenta la favorabilidad de la inclusión social. Los resultados del test t mostraron que el proyecto cumpla sus objetivos sólo en parte porque no hubo diferencias significativas en relación a la favorabilidad a la inclusión escolar entre el grupo de tratamiento y el grupo control. Como complemento, el análisis de contenido, hemos identificado cinco categorías relacionadas con los aspectos de procedimiento y resultados del proyecto, a saber: (i) la participación de la familia; (ii) las formas de comunicación; (iii) la movilidad; (iv) el empleo y generación de ingresos; y (v) la inclusión social. Los resultados de la investigación fueron discutidos desde el marco teórico. Recomendaciones para el proyecto y sugerencias para futuras investigaciones se realizan.

Palabras-claves: Carnaval, minusválidos, inclusión, programas.

\section{I ntrodução}

É crescente a demanda por ações sociais voltadas para diferentes formas de inclusão social e alternativas para a promoção do desenvolvimento humano, com base na ideia de um mundo mais ético e com maior justiça social, econômica, ambiental e moral. Nas últimas décadas registra-se o crescimento de organizações políticas de defesa dos interesses das pessoas com deficiência (Barros, 2015), bem como o aumento na discussão em torno da inclusão social, tema que ganhou maior relevância com o lançamento da Política Nacional de Educação Especial na Perspectiva da Educação Inclusiva (MEC, 2008) e com a instituição da Lei Brasileira de Inclusão da Pessoa com Deficiência, Lei 13.146/2015, "destinada a assegurar e a promover, em condições de igualdade, o exercício dos direitos e das liberdades fundamentais por pessoa com deficiência, visando à sua inclusão social e cidadania" (Estatuto da Pessoa com Deficiência, 2015).

Lima e Jurdi (2014) confirmam certo avanço do Brasil acerca dos 
direitos e legislações direcionados às pessoas com deficiência para buscar a inclusão dessas pessoas na esfera do trabalho e renda como forma de garantir a valorização do indivíduo, que ao realizar atividades laborais se sente parte integrante e ativa nas relações sociais cotidianas. Apontamento semelhante também resultou das pesquisas de Volz et al. (2015).

Mas não basta que sejam criados programas sociais ou programas inclusivos. Torna-se necessário avaliar seus resultados. O conceito de avaliação tem relação direta com aquilo que precisa ser conhecido, examinado, julgado e ter estabelecido um valor (Worthen, Sanders, \& Fitzpatrick, 2004). Mourão e Laros (2008) assinalam que a avaliação deve ser baseada em metas e objetivos, de forma a auxiliar o gestor na tomada de decisões em busca de melhores resultados.

Avaliações fundamentadas na Psicologia podem: contribuir para propor intervenções em determinada realidade social; levar os membros de uma comunidade a questionar o seu verdadeiro papel; e desenvolver capacidades empreendedoras a partir do autoconhecimento adquirido (Fernandez-Ballesteros, Vedung, \& Seyfried, 1998; Murta, Laros \& Tróccoli, 2005). A avaliação de programas sociais, sob a ótica da Psicologia Social, apresenta-se como uma desafiadora tarefa em relação àquilo que se pode esperar do processo de avaliação como um todo (Almeida, 2006). A participação e o envolvimento dos grupos de interesse (stakeholders) são de fundamental importância no processo de avaliação (Furtado, 2001).

Diante desse contexto, cresce no Brasil o interesse das empresas e de suas fundações em conhecer os efeitos das intervenções nas causas sociais que defendem. De acordo com Peliano (2009), esse fenômeno foi impulsionado em meados da década de 1990 e, agora, toma contornos novos e diferenciados. Se no passado, a empresa diferente era a que realizava alguma ação social, atualmente, a preocupação é com a qualidade dessas ações e em saber os resultados que elas produzem.

O Instituto de Pesquisa Econômica Aplicada - I pea têm investigado a participação do setor privado em atividades direcionadas às comunidades mais pobres da população brasileira. Em 2002, foi divulgada a primeira Pesquisa Ação Social das Empresas - Pase, com o objetivo de investigar: (i) o envolvimento das empresas na área social; (ii) as características desse envolvimento; e (iii) a magnitude do atendimento. Das 445 mil empresas privadas avaliadas, houve um predomínio das empresas comerciais $(49 \%)$ e empresas com menos de dez empregados (58\%). A pesquisa mostrou que dois terços das empresas realizam algum tipo de ação social para a comunidade, que vai desde pequenas doações até projetos mais bem estruturados (Ipea, 2002).Na pesquisa do Ipea de2006, fica evidenciado que cresceu o número de empresas que realizam algum tipo de ação 
social para a comunidade onde estão inseridas, passando de $59 \%$, em 2000, para 69\%, em 2004 (I pea, 2006). Assim, o crescimento dos investimentos na área social impulsiona também a avaliação de programas.

Diante de tal cenário, o objetivo deste estudo foi avaliar o Projeto Embaixadores da Alegria, desenvolvido pela associação escola de samba homônima, tendo como principal financiador a empresa Furnas Centrais Elétricas S.A. e contando com a parceria de diversas instituições com destaque para a Universidade Estácio de Sá e a Liga das Escolas de Samba do Grupo Especial. As razões para a escolha desse Projeto foram: (i) a relevância temática e a atualidade das discussões sobre a inclusão social de pessoas com deficiência; (ii) o amplo número de pessoas atingidas pelo Projeto; (iii) a avaliabilidade do mesmo, uma vez que a instituição responsável concordou com a avaliação e disponibilizou dados necessários à pesquisa.

O Projeto Embaixadores da Alegria levou para o Carnaval de 2015 um desfile com 1.500 pessoas e no período de 2011 a 2015 contemplou uma média de 1.560 pessoas (desvio-padrão $=151$ ), o que sinaliza para uma regularidade no público dos desfiles. O Projeto tem como objetivo geral promover a inclusão social das pessoas com quaisquer tipos de deficiência, utilizando a arte e a cultura do Carnaval como ferramentas para a construção de relações mais harmônicas com seus familiares, com outros deficientes e com não deficientes. Os objetivos específicos do Projeto são: (i) oferecer cursos e oficinas profissionalizantes, abrindo possibilidades de inserção no mercado de trabalho; (ii) possibilitar certificação para os alunos que concluírem os cursos; (iii) incluir o deficiente e seus familiares em um mercado de trabalho em expansão; (iv) possibilitar a participação dos alunos e familiares no desfile de Carnaval.

\section{Método}

O método empregado foi de um estudo de caso, pois se pesquisou um fenômeno social dentro do seu próprio contexto de vida, explorando múltiplas fontes de evidências (Yin, 2009). O estudo de caso mostrou-se uma estratégia apropriada por tratar-se de investigação empírica caracterizada como pesquisa naturalística e por reunir grande quantidade de informações, dados e evidências, ampliando a confiabilidade e validade dos achados (Martins, 2008).

O Projeto teve início em março de 2010 e envolveu etapas de seleção dos beneficiários, realização das oficinas, formação do conselho de professores e avaliação. O grupo de executores do Projeto desenvolve diferentes papéis, incluindo coordenação, instrução, monitoria e fisioterapia (Projeto Embaixadores da Alegria, 2009).

O estudo, de corte transversal, propôs-se a verificar em que medida 
o Projeto obteve êxito (análise pós-facto), considerando como ponto de partida a análise dos objetivos propostos. Assim, para verificar se a inclusão social pretendida de fato ocorreu, foram comparadas as respostas de um grupo de pessoas que convive com deficientes participantes do Projeto (grupo de tratamento) e as respostas de um grupo de controle natural (com as mesmas características do grupo principal, exceto pela inexistência de contato com as pessoas deficientes participantes do Projeto).

A razão para a escolha desses grupos se deu porque se almeja que a convivência com pessoas deficientes participantes do Projeto sirva para despertar nas pessoas uma maior consciência acerca da importância da inclusão social. Nesse sentido, espera-se que as pessoas que convivem com os participantes do Projeto Embaixadores da Alegria mudem a sua atitude sobre a inclusão social não apenas em termos de participação no Carnaval, mas em termos da participação das pessoas com deficiência na vida da sociedade de um modo geral. Entende-se que este seria um dos objetivos centrais do Projeto, porque o Carnaval é considerado, nos Embaixadores da Alegria, como instrumento para ampliar essa conscientização acerca da importância da inclusão social de pessoas com deficiência.

Portanto, se a convivência com os participantes do Projeto servir para aumentar a favorabilidade à inclusão escolar, a Aceitação da inclusão escolar e a favorabilidade à inclusão social de um modo geral (variáveis testadas no teste $\mathrm{t}$ ), este será um indicador de que o objetivo maior do Projeto Embaixadores da Alegria está sendo alcançado, pois ele estará sendo capaz de mudar as atitudes das pessoas em termos de ampliar a favorabilidade à inclusão em diferentes contextos sociais.

Sendo assim, a abordagem metodológica survey foi utilizada com beneficiários e seus familiares, e também com membros da comunidade. Entrevistas individuais e em grupo com os demais stakeholders complementaram e aprofundaram a avaliação.

Para planejar e executar a avaliação do Projeto Embaixadores da Alegria adotou-se a ferramenta do marco lógico, desenvolvida pela United States Agency for International Development - USAID. Essa ferramenta baseia-se num processo de hierarquização de objetivos associados ao Projeto, com identificação dos seus respectivos indicadores, metas, fontes de verificação e pressupostos básicos (Mourão \& Meneses, 2012).

\subsection{Participantes}

O presente estudo contemplou 538 pessoas, incluindo vários atores do Projeto. A Tabela 1 detalha o perfil dos diferentes stakeholders que foram pesquisados. 
Tabela1

Descrição do Perfil dos Stakeholders e dos Métodos de Coleta de Dados

\begin{tabular}{|c|c|c|}
\hline $\begin{array}{c}\text { Stakeholders/ } \\
\text { Método de } \\
\text { coleta }\end{array}$ & Descrição & Perfil do pesquisado \\
\hline \multirow[t]{3}{*}{$\begin{array}{l}\text { Gestores do } \\
\text { Projeto } \\
\text { (Entrevista em } \\
\text { profundidade) }\end{array}$} & \multirow[t]{3}{*}{$\begin{array}{l}\text { Profissionais } \\
\text { que atuam } \\
\text { diretamente na } \\
\text { gestão do } \\
\text { Projeto }\end{array}$} & $\begin{array}{l}\text { Gestor 1: um dos idealizadores } \\
\text { do Projeto. Sua atuação dá-se na } \\
\text { forma de direção, pensamento } \\
\text { estratégico, formas de atuação e } \\
\text { formação de parcerias com foco } \\
\text { na autossustentabilidade do } \\
\text { Projeto. }\end{array}$ \\
\hline & & $\begin{array}{l}\text { Gestor 2: profissional atuante no } \\
\text { mercado de publicidade e } \\
\text { marketing, também é um dos } \\
\text { idealizadores do Projeto e tem } \\
\text { atuação correlata ao do gestor } 1 \text {. }\end{array}$ \\
\hline & & $\begin{array}{l}\text { Gestor 3: atua na organização } \\
\text { administrativa do Projeto, realiza } \\
\text { orçamentos, pagamentos, } \\
\text { contatos, contratos com } \\
\text { professores e fornecedores. }\end{array}$ \\
\hline \multirow[t]{2}{*}{$\begin{array}{l}\text { Financiadores } \\
\text { (Entrevista em } \\
\text { profundidade) }\end{array}$} & \multirow[t]{2}{*}{$\begin{array}{l}\text { Empresas que } \\
\text { apoiam } \\
\text { financeiramente } \\
\text { o Projeto }\end{array}$} & $\begin{array}{l}\text { Financiador 1: profissional com } \\
\text { formação em Serviço Social e que } \\
\text { atua na elaboração, } \\
\text { acompanhamento, monitoramento } \\
\text { e avaliação técnica de projetos e } \\
\text { programas sociais. }\end{array}$ \\
\hline & & $\begin{array}{l}\text { Financiador 2: profissional com } \\
\text { formação em Serviço Social e } \\
\text { Pedagogia. Também atua na } \\
\text { elaboração, acompanhamento, } \\
\text { monitoramento e avaliação } \\
\text { técnica de projetos e programas } \\
\text { sociais. }\end{array}$ \\
\hline $\begin{array}{l}\text { Executores } \\
\text { (Entrevista em } \\
\text { profundidade) }\end{array}$ & $\begin{array}{l}\text { Professores } \\
\text { com } \\
\text { qualificação } \\
\text { para atuar na } \\
\text { execução das } \\
\text { oficinas do } \\
\text { Projeto }\end{array}$ & $\begin{array}{l}\text { Professor 1: sexo masculino, } 30 \\
\text { anos e atua no ramo de } \\
\text { coordenação artistica. } \\
\text { Professor 2: sexo masculino, } 34 \\
\text { anos, atua com pintura com } \\
\text { motivos carnavalescos. } \\
\text { Professor 3: sexo masculino, } 34 \\
\text { anos e atua na área de desenho. }\end{array}$ \\
\hline
\end{tabular}




\begin{tabular}{|c|c|c|}
\hline \multirow[t]{2}{*}{$\begin{array}{l}\text { Beneficiários } \\
\text { e familiares } \\
\text { (Questionário e } \\
\text { entrevista em } \\
\text { profundidade) }\end{array}$} & $\begin{array}{l}\text { Familiares } \\
\text { participantes }\end{array}$ & $\begin{array}{l}\text { Mãe 1: } 53 \text { anos, do lar e participa } \\
\text { do Projeto desde } 2009 \text {. } \\
\text { Mãe 2: } 61 \text { anos, do lar e participa } \\
\text { do Projeto desde } 2009 \text {. } \\
\text { Mãe 3: } 68 \text { anos, aposentada e } \\
\text { participa do Projeto desde } 2010 \text {. } \\
\text { Mãe 4: } 49 \text { anos, do lar e participa } \\
\text { do Projeto desde } 2010 \text {. } \\
\text { Mãe 5: } 81 \text { anos, do lar e está no } \\
\text { Projeto desde } 2010 \text {. } \\
\text { Mãe 6: } 50 \text { anos, costureira, está } \\
\text { no Projeto desde } 2011 \text {. } \\
\text { 27 familiares, com idade média } \\
\text { de } 55,3 \text { anos (DP=10,8), sendo } \\
96,4 \% \text { do sexo feminino }\end{array}$ \\
\hline & $\begin{array}{l}\text { Deficientes } \\
\text { participantes }\end{array}$ & $\begin{array}{l}27 \text { participantes, com idade } \\
\text { média de } 25,1 \text { anos (DP=9,4), } \\
\text { sendo } 55,6 \% \text { do sexo masculino, } \\
\text { incluindo pessoas com deficiência } \\
\text { fisica, visual e intelectual. } \\
\text { Nenhum deficiente auditivo fez } \\
\text { parte da amostra da pesquisa. }\end{array}$ \\
\hline \multirow[t]{2}{*}{$\begin{array}{l}\text { Membros da } \\
\text { Sociedade } \\
\text { (Questionário) }\end{array}$} & $\begin{array}{l}\text { Grupo } \\
\text { Tratamento }\end{array}$ & $\begin{array}{l}226 \text { Alunos de escolas públicas } \\
\text { que convivem com deficientes } \\
\text { participantes do Projeto: } \\
58,6 \% \text { do sexo feminino; com } \\
\text { idade média de } 16,9 \text { anos } \\
\text { (DP }=7,5) \text {, com média de estudo } \\
\text { de } 8,3 \text { anos (DP }=1,5 \text { ) }\end{array}$ \\
\hline & Grupo Controle & $\begin{array}{l}244 \text { Alunos de escolas públicas } \\
\text { que não convivem com } \\
\text { deficientes participantes do } \\
\text { Projeto: } 54,3 \% \text { do sexo } \\
\text { feminino; com idade média de } \\
14,9 \text { anos (DP }=3,0) \text {, com média } \\
\text { de } 8,4 \text { anos de estudo ( } D P=1,5)\end{array}$ \\
\hline
\end{tabular}

\subsection{I nstrumentos de coleta de dados}

Para cada público-alvo e técnica de coleta de dados foi utilizado um instrumento específico. Beneficiários e familiares preencheram a um questionário com perguntas sobre os processos e os resultados do Projeto. Os membros da comunidade responderam ao Inventário Geral de Atitudes em Relação à Educação Inclusiva - IGAEI, desenvolvido e com evidências de validade psicométrica apontadas por Barbosa, Rosini e Pereira (2007). O IGAEI é formado por 32 sentenças abrangendo crenças, sentimentos e tendências de ação perante a inclusão escolar, sendo cada sentença associada a uma escala de concordância, tipo Likert, variando de 1 (concordo totalmente) a 5 (discordo totalmente). São exemplos de itens deste inventário: "Deve-se dar aos portadores de necessidades educacionais especiais tantas oportunidades quantas sejam necessárias para incluírem-se em uma classe regular"; e "É difícil manter a disciplina em uma sala de aula regular que tenha um ou 
mais portadores de necessidades educacionais especiais".

Tendo em vista que o IGAEI está focalizado exclusivamente na inclusão educacional, foram criados oito itens abordando a temática da inclusão das pessoas com necessidades especiais a partir da arte, da cultura e do papel do Estado. Esses itens compuseram uma nova escala de favorabilidade à inclusão social em diferentes contextos, que foi desenvolvida especificamente para esta pesquisa e que teve sua validade psicométrica testada na amostra deste estudo. Assim como o IGAEl, esse novo instrumento também era respondido por uma escala de concordância de cinco pontos. São exemplos de item dessa escala: "Pessoas com necessidades especiais também têm o direito de uma vida de qualidade" e "O Estado deve encorajar os cidadãos a promoverem a aceitação de pessoas com necessidades especiais nos mais diversos ambientes".

\subsection{Procedimentos de coleta e análise de dados}

A pesquisa foi autorizada por Furnas e pela Escola de Samba Embaixadores da Alegria e aprovada por um comitê de ética.Os procedimentos de coleta de dados foram: (i) análise documental; (ii) realização de entrevistas em profundidade; e (iii) aplicação de questionários. Todos os participantes assinaram o Termo de Consentimento Livre e Esclarecido (TCLE) e Ihes foi garantido o direito de sigilo das informações individuais e de conhecer os resultados da mesma.

A análise dos dados quantitativos foi realizada com o auxílio do software SPSS, versão 22.0. As estatísticas utilizadas foram: (i) análise descritiva; (ii) análise das evidências de validade psicométrica do IGAEI e da escala sobre inclusão social criada especificamente para esta pesquisa; (iii) teste t para comparação dos escores médios obtidos entre os grupos (de tratamento e controle). Para o tratamento dos documentos do Projeto e das entrevistas foi feita análise de conteúdo categorial (Bardin, 1977; Bauer, 2010), com agrupamento de elementos de significados mais próximos, com formação de categorias e subcategorias. Finalmente, foram conduzidas análises tendo-se por base a técnica da triangulação, que permitiu identificar divergências e similitudes de resultados obtidos a partir de diferentes métodos de coleta e também de diferentes stakeholders.

\section{Resultados}

Com o objetivo de preservar a identidade dos pesquisados, cada participante recebeu um código, sendo as falas numeradas da seguinte forma: Financiador 1, Financiador 2, Mãe 1, Mãe 2e, assim, sucessivamente. $\mathrm{Na}$ análise de conteúdo, foram identificadas cinco 
categorias, sendo as três primeiras relacionadas a aspectos processuais do Projeto: (i) participação da família; (ii) formas de comunicação; e (iii) mobilidade; e as outras duas categorias voltadas para os resultados obtidos: (iv) trabalho e geração de renda; e (v) inclusão social.

A categoria Participação da família busca valorizar a atuação dos pais/responsáveis pelo Projeto, sobretudo das mães, o que proporciona segurança e motivação para a realização das atividades. Essa categoria dividiu-se em três subcategorias: Participação familiar como diferencial; Projeto participativo; e Segurança dos alunos participantes. Um dos gestores frisou em seu depoimento que "a participação da família ou dos responsáveis no projeto é de fundamental importância para que o aluno alcance os objetivos propostos".

A categoria Formas de comunicação emergiu como importante ferramenta para a disseminação do conhecimento, das formas de divulgação, da visibilidade, da contrapartida e a da questão da sustentabilidade do Projeto. O próprio desfile das campeãs foi apontado como uma forma de comunicação e divulgação dos resultados. A categoria Formas de comunicação dividiu-se nas subcategorias Sustentabilidade, Conhecimento do Projeto e Visibilidade.

A Mobilidade é vista pelos stakeholders do Projeto Embaixadores da Alegria como um desafio a ser superado para não prejudicar o direito de ir e vir de cada um, tendo sido identificadas duas subcategorias: Possibilidade de locomoção e Acessibilidade. A preocupação aqui refere-se a temas como dificuldades de acesso; inexistência de rampas para idosos, cadeirantes e outros deficientes; falta de preocupação das autoridades públicas com a questão; e o custo alto das passagens de transporte coletivo.

A temática Trabalho e geração de renda esteve presente nos depoimentos dos grupos pesquisados, sendo possível identificar dois agrupamentos dessa categoria: Geração de renda e Terapia ocupacional remunerada, de forma que os participantes acreditam que as oficinas desenvolvidas pelo Projeto auxiliam no aprendizado de habilidades que podem ser transformadas em trabalho e renda.

Como seria de se esperar, o tema inclusão social apareceu como importante categoria nas falas das pessoas envolvidas com o Projeto. Essa categoria subdividiu-se em três subcategorias: Igualdade, Aprendizagem e Relacionamento/Diálogo. Foram vários os depoimentos que abordaram a temática, provenientes das variadas fontes de coleta de dados, por exemplo:

- "Acho um trabalho, assim, muito importante que faz essa inclusão com as crianças" (Mãe);

- "O Projeto tem um potencial bom, quando promove a 
integração e inclusão dos deficientes físicos através da arte do Carnaval" (Financiador);

- “O Projeto está criando uma plataforma e um núcleo de alegria que gera inclusão para todos e uma alternativa para a exclusão que acontece na sociedade" (Gestor);

- "O Projeto contribui para a inclusão social, para o aprendizado sobre a cultura, para o desenvolvimento motor e mental de muitos e para estar se profissionalizando mesmo" (Professor).

Esse conjunto de depoimentos confirma que algumas categorias (como a de inclusão social) são percebidas pelos stakeholders, com considerável similitude de opiniões. Uma síntese das categorias e subcategorias que emergiram da análise de conteúdo é mostrada na Figura 1.

PARTICIPAC̣ÃODAFAMIIIIA

- Participação familiar como diferencial - "Ten algo de especial que é un diferencial nos Embadxadores de colocar o responsável e o deficiente. Isso nós não venos em outos lugares" (Mãe 1).

- Projeto participativo - "Se eles não gostam, eles não gostam mesmo! Eu percebi que o desenho não estava funcionando comeles. Daieu resohi trazer de cas a wnas bonequin has efoi ai que eles gostaram e passaramadesenhar". (Professor 3).

- Segurança dos a lunos partidipantes - "Ele não estava acostumado a fazer nada de camaval Para ele a importância é muito grande, e eu estan do do lado dele, ele tem mais segurança " (Mäe 3).

\section{FORMAS DE COMUNICAC̣AO}

- Sustentabilidade - "Também há a questão da sustenta bilidade do projeto que, entendo, deve ser buscada por meio dap articipação de mais parceivos institucionais "(Financiador 2).

- Conhedimen to do projeto - "A divulgação do conheximento sobre as atvidades desenvo hidas pelo projeto pode ser feito de boca a boca, nas co nversas entre os participantes" (Financiador 2).

-Visibilida de - "Este ano tviemos algo em tomo de 5 a 6 mil pessoas querendo desfilar conosco, apenas no Rio e infelizmente, temos limitagäáo de 1.700 pessoas, uncarno e tempo para desfilar" (Gestor 1).

\section{MOBாIDADE}

- Possibilidade de locomoção - "Hoje meu filho não veio, pois o cartão do transporte dá para 60 dias $e$ chegando nessa quantidade de dias, ele bloqueiaautomaticamente e só libera no mês seguinte" (Mãe 3 ).

- Acessibilidade - "O espaço já está todo destinado para eles, nós modificamos, colocamos rampas, -corrimão nos banheivos" (Professor 3).

\section{TRABALHOEGERAÇÁODE RENDA}

- Geração de renda - "Nós temos a questão do mercado de trabalho, as oficinas direcionadas para isso, una fontede renda para cada un (...). Aqui eles oferecem isso para nós" (Mãe 1).

- Terapia ocupacional remunerada - "Outra mãe levou as coisas que eu fiz de pintura e vendeu três para mim e enquanto eu puder fazer paravender, eu vou vender" (Mãe 6).

\section{INCLUSAOO SOCLAL}

- Igualdade- "Chana a atenção a questão da igualdade pres ente em todas as ações do projeto. Não há exchusão das pessoas, seja qual for o tipo de dificuldade apresentada" (Financiador 1).

-Aprendizagem - "O projeto contribui paraa inclusão social, para o aprendizado sobrea cultura, para o desenvolvimento motor emental de muito se para estar seprofissionalizandomesmo" (Professor 1).

- Relacionamento/Diálogo - "Existe wna aberturagrande da gente ter esse diálogo ento todos eles $e$ nós e as crianças, com extremo respeito. (...) Não tem esse negócio de vir de cima prá cá não" (Mãe 3).

Figura 1. Categorias e subcategorias originárias da análise de conteúdo das entrevistas. 
No que diz respeito à análise fatorial do IGAEI, embora a testagem original do instrumento tivesse três fatores (Barbosa et al., 2007), na presente pesquisa a solução de dois fatores foi a que conseguiu agrupamento de itens de proximidade semântica e valores aceitáveis de fidedignidade. Assim, foram extraídos o Fator 1: Favorabilidade à inclusão escolar (Alfa de Cronbach $=0,74,12$ itens) e o Fator 2: Aceitação da inclusão escolar (Alfa de Cronbach $=0,60,3$ itens). Em relação aos itens de inclusão social na sociedade como um todo (e não apenas na escola), foi feita uma análise fatorial dos oito itens desenvolvidos especificamente para a avaliação deste Projeto. O KMO $(0,89)$ indicou boas condições de análise da matriz de dados. A estrutura fatorial obtida foi de um único fator, conforme resultado da análise paralela e screeplot, sendo confirmada uma única dimensão denominada de Favorabilidade à inclusão social, que apontou grau de precisão satisfatório (Alfa de Cronbach $=0,84,8$ itens) e cargas fatoriais elevadas, variando de 0,61 a 0,71 .

Para estudar o impacto do Projeto, foram comparadas as respostas do grupo de tratamento e do grupo controle. Assim, com base no teste $\mathrm{t}$ realizado, os resultados mostram que os fatores de inclusão escolar e de inclusão social apresentam médias distintas entre os dois grupos pesquisados (grupo tratamento e grupo controle) como pode ser visto na Tabela 2, sendo que no primeiro caso, a média diferenciou-se apenas na dimensão de aceitação da inclusão.

\begin{tabular}{|c|c|c|c|c|c|}
\hline Variáveis & $\begin{array}{c}\text { Grupos } \\
\text { pesquisados }\end{array}$ & $\mathbf{N}$ & Média & $\begin{array}{l}\text { Desvio } \\
\text { padrão }\end{array}$ & Teste $t$ \\
\hline \multirow{2}{*}{$\begin{array}{c}\text { Favorabilidade } \\
\text { à inclusäo } \\
\text { escolar }\end{array}$} & $\begin{array}{c}\text { Grupo } \\
\text { Tratamento } \\
\end{array}$ & 228 & 3,42 & 0,50 & \multirow{2}{*}{$\begin{array}{l}\mathrm{t}=1,76 \\
\mathrm{gl}=448 \\
\mathrm{p}<0,78\end{array}$} \\
\hline & Grupo Controle & 222 & 3,50 & 0,55 & \\
\hline \multirow{2}{*}{$\begin{array}{l}\text { Aceitação da } \\
\text { inclusão } \\
\text { escolar }\end{array}$} & $\begin{array}{c}\text { Grupo } \\
\text { Tratamento }\end{array}$ & 228 & 3,09 & 0,75 & \multirow{2}{*}{$\begin{array}{l}\mathrm{t}=-5,79 ; \\
\mathrm{gl}=448 ; \\
\mathrm{p}<0,01\end{array}$} \\
\hline & Grupo Controle & 222 & 2,61 & 1,01 & \\
\hline \multirow{2}{*}{$\begin{array}{c}\text { Favorabilidade } \\
\text { à inclusão } \\
\text { social }\end{array}$} & $\begin{array}{c}\text { Grupo } \\
\text { Tratamento }\end{array}$ & 228 & 3,77 & 0,68 & \multirow{2}{*}{$\begin{array}{l}\mathrm{t}=8,71 ; \\
\mathrm{gl}=448 ; \\
\mathrm{p}<0,01\end{array}$} \\
\hline & Grupo Controle & 222 & 4,28 & 0,53 & \\
\hline
\end{tabular}

Os beneficiários e familiares participaram, em média, de 1,2 oficinas $(D P=0,93)$, sendo que as mais frequentadas foram: maquiagem artística (37\%) e história da arte aplicada ao Carnaval (18,5\%). As oficinas desenho de figurino, reciclagem em garrafas PET, aderecista e informática para a indústria do Carnaval tiveram um percentual de participação inferior às demais. A maioria dos pesquisados (36\%) participou uma vez do desfile e $32 \%$ ainda não participou de nenhum desfile. Participantes em dois desfiles equivalem a $23 \%$ do total e $9 \%$ 
participou de três ou mais desfiles.

Em relação à pergunta sobre a importância que o Projeto Embaixadores da Alegria tem na vida dos beneficiários e familiares, numa escala de 0 a 10, o grau médio de importância foi de 9,3 ( $\mathrm{DP}=1,1 \mathrm{em}$ ambos os casos). Essa média tão elevada sugere que beneficiários e familiares atribuem grande valor ao Projeto.

Mas a despeito desse resultado, a avaliação do Embaixadores da Alegria permitiu concluir que o objetivo geral do mesmo não foi totalmente atingido. Os indicadores definidos foram: número de participantes do Projeto empregados, médias de favorabilidade à inclusão escolar e social de pessoas com deficiência e número de participantes do Carnaval. Quanto a ser favorável à inclusão escolar e social, os resultados do teste t não indicaram diferenças significativas em relação à inclusão escolar, embora a aceitação da inclusão escolar tenha sido mais elevada no grupo de tratamento que no grupo controle. Contudo, a média de favorabilidade à inclusão social foi menor no grupo de tratamento, o que se opõe ao resultado de maior aceitação social das pessoas com deficiência nas comunidades nas quais elas estão inseridas. Quanto ao terceiro indicador, o número de participantes previsto para o desfile das campeãs, o total de participantes foi de 1.800 , atingindo a meta prevista pelos gestores do Projeto.

Apesar de não haver indicadores específicos de geração de renda, observa-se que as oficinas têm proporcionado aos participantes diversas formas de obtenção de renda, ao realizar a venda de produtos artesanais confeccionados a partir da participação no Projeto. Percebe-se, nos depoimentos, que a atuação dos deficientes e seus familiares nas oficinas contribui para que eles consigam vender produtos, com possível aumento de renda familiar. Contudo, não foi identificado um acolhimento no mercado de trabalho por parte dessas pessoas, como consequência esperada do processo de inclusão social.

Quanto às "relações mais harmônicas com os familiares e com outros deficientes e com outros não deficientes", há depoimentos que indicam melhorias, sobretudo na relação com familiares, com participantes que se tornaram mais comunicativos e extrovertidos. Além disso, a participação da família no Projeto amplia as horas de convivência, favorece a realização de tarefas em comum e fortalece as relações familiares.

Quanto aos objetivos específicos ou propósitos do Projeto, cada um teve o seu respectivo indicador: número de curso e oficinas realizadas; número de alunos/familiares atendidos; nível de satisfação com o tipo de treinamento recebido para geração de trabalho e renda; e número de participantes no desfile de Carnaval.

O número de oficinas realizadas foi cumprido, conforme relatório da instituição. Além disso, entre os beneficiários que responderam ao 
questionário avaliativo, $81,5 \%$ participaram de pelo menos uma oficina profissionalizante, o que confirma a aceitação do Projeto pela maioria. O número de pessoas com deficiência atendidas não atingiu a meta inicialmente estabelecida de 400 pessoas. Foram atendidas 239 pessoas com deficiência, 150 pais e responsáveis e 51 amigos. Assim, foi alcançado $60 \%$ da meta prevista, embora o número total de pessoas atingidas tenha sido de 440 . O número de participantes do Carnaval teve aumento, sendo 1.200 participantes em 2010 e 1.500 em 2015. A pesquisa com beneficiários e familiares também mostrou uma participação expressiva nos desfiles, pois $68 \%$ dos respondentes desfilaram pelo menos uma vez no desfile das campeãs.

Por fim, o nível de satisfação com as oficinas voltadas para a inclusão dos participantes no mercado de trabalho foi em geral positivo. Considerando a escala de 1 a 5, os resultados mostraram satisfação em relação à contribuição do Projeto para a inserção social $(M=4,5$; $\mathrm{dp}=0,6$, para beneficiários e $M=4,6 ; d p=0,5$ para familiares); bem como percepção de aumento de chances no mercado de trabalho $(M=4,0 ; \quad d p=0,9$, para beneficiários e $M=4,0 ; \quad d p=1,0$ para familiares).já em relação à existência de certificação para aqueles que participam das oficinas do Projeto Embaixadores da Alegria, a média foi mais baixa $(M=3,0 ; d p=1,3$, tanto para beneficiários como para familiares).

A referência à certificação é relevante não só porque diz respeito a um dos objetivos do Projeto, mas também porque a certificação é um recurso para os participantes conseguirem inserção no mundo do trabalho. Então, o fato de muitos não estarem recebendo os certificados é um resultado negativo. Uma análise geral dos resultados da avaliação do Projeto é apresentada, na Tabela 3, à luz do marco lógico construído para essa avaliação. 
Tabela 3

Resultados da Avaliação do Projeto Embaixadores da Alegria à Luz do Marco Lógico

\begin{tabular}{|c|c|c|c|c|c|}
\hline \multirow{2}{*}{\multicolumn{2}{|c|}{ Objetivos }} & \multicolumn{3}{|c|}{ Indicadores } & \multirow{2}{*}{$\begin{array}{l}\text { Meios de } \\
\text { verific ação }\end{array}$} \\
\hline & & Descrição & Previsto & Realizado & \\
\hline \multirow{3}{*}{$\begin{array}{l}\text { Objetivo geral } \\
\text { ou de impacto }\end{array}$} & \multirow{3}{*}{$\begin{array}{l}\text { Promover a inclusão social das pessoas com } \\
\text { quaisquer tipos de deficiência, utilizando a } \\
\text { arte e a cultura do carnaval como } \\
\text { ferramentas para a construção de relações } \\
\text { mais harmônicas com seus familiares, com } \\
\text { outros deficientes e com outros não- } \\
\text { deficientes. }\end{array}$} & $\mathrm{N}^{0}$ de participantes do projeto empregados & $\begin{array}{l}\text { Não havia } \\
\text { metas } \\
\text { estabelecidas }\end{array}$ & $\begin{array}{c}\text { Não informado, embora } \\
\text { entrevistas indiquem aumento } \\
\text { de renda em função de produtos } \\
\text { vendidos }\end{array}$ & Entrevista \\
\hline & & $\begin{array}{l}\text { Média de favorabilidade à inclusão social e } \\
\text { escolar }\end{array}$ & $\begin{array}{l}\text { Não havia } \\
\text { metas } \\
\text { estabelecidas }\end{array}$ & $\begin{array}{c}\text { Média de aceitação da inclusão } \\
\text { escolar superior no grupo de } \\
\text { tratamento e média de } \\
\text { favorabilidade à inclusão social } \\
\text { superior no grupo controle }\end{array}$ & $\begin{array}{l}\text { Estudo quase- } \\
\text { experimental } \\
\text { (teste } t)\end{array}$ \\
\hline & & $\mathrm{N}^{0}$ de participantes do carnaval & 1700 & 1800 & $\begin{array}{l}\text { Relatórios da } \\
\text { instituição }\end{array}$ \\
\hline \multirow{4}{*}{$\begin{array}{l}\text { Objetivos } \\
\text { especificos }\end{array}$} & $\begin{array}{c}\text { Oferecer cursos e oficinas } \\
\text { profissionalizantes ministradas em parceria } \\
\text { com o Institu to do Carnaval da Universidade } \\
\text { Estácio de Sá, abrindo possibilidades de } \\
\text { inserção no mercado de trabalho. }\end{array}$ & $\mathrm{N}^{0}$ de cursos e oficinas & 10 & 10 & $\begin{array}{l}\text { Relatórios da } \\
\text { instituição }\end{array}$ \\
\hline & $\begin{array}{l}\text { Possibilitar certificação para todos os alunos } \\
\text { que concluirem os cursos }\end{array}$ & $\mathrm{N}^{0}$ de beneficiários atendidos & 400 & 239 & $\begin{array}{l}\text { Relatórios da } \\
\text { instituição }\end{array}$ \\
\hline & $\begin{array}{l}\text { Incluir o deficiente e seus familiares em um } \\
\text { mercado de trabalho em grande expansão. }\end{array}$ & $\begin{array}{l}\text { Nivel de satisfação com o tipo de } \\
\text { treinamento recebido para tal finalidade }\end{array}$ & $\begin{array}{l}\text { Não havia } \\
\text { metas } \\
\text { estabelecidas }\end{array}$ & $\begin{array}{l}\text { Média elevada de satisfação } \\
\text { com a participação no projeto } \\
(\mathrm{M}=4,5 ; \mathrm{DP}=0,57) \text { e com o } \\
\text { aumento das chances de } \\
\text { inserção no mercado de } \\
\text { trabalho }(\mathrm{M}=4,0 ; \mathrm{DP}=0,94)\end{array}$ & $\begin{array}{l}\text { Pesquisa de } \\
\text { satisfação (escala } \\
\text { de mensuração } \\
\text { variando de } 1 \text { a } \\
\text { 5) }\end{array}$ \\
\hline & $\begin{array}{l}\text { Possibilitar a participação de alunos e } \\
\text { familiares no desfile de carnaval de } 2010 \text {. }\end{array}$ & $\mathrm{N}^{0}$ de participantes & 1000 & 1200 & $\begin{array}{l}\text { Relatórios da } \\
\text { instituição }\end{array}$ \\
\hline
\end{tabular}




\section{Discussão}

As respostas dos stakeholders foram comparadas para verificar a coerência nos discursos entrevistados, caracterizando uma triangulação das fontes de resposta. Verificou-se também se havia ou não coerência entre os dados obtidos na abordagem quantitativa e na abordagem qualitativa. No que diz respeito à percepção dos stakeholders, a análise da presença e ausência da abordagem das categorias e subcategorias, mostra sintonia entre os depoimentos. Vários foram os conteúdos que estiveram presentes nas falas dos diferentes atores participantes do Projeto: beneficiários, familiares, financiadores, gestores e executores.

Merece destaque a categoria inclusão social - objetivo geral do Projeto - e que esteve presente de forma direta e espontânea nos depoimentos das diferentes fontes pesquisadas. Essa preocupação com a inclusão social ratifica o atual debate nacional e internacional sobre a temática e permite impulsionar e provocar movimentos sociais e ações políticas (Mazzotta \& D'Antino, 2011).O Projeto também contribui com a perspectiva da educação inclusiva como uma ação política, cultural, social e pedagógica que defende o direito de todos os estudantes de estarem juntos (MEC, 2008).

Para todas as categorias e subcategorias buscou-se apresentar análises que ilustrassem as percepções dos stakeholders, ficando evidenciada a coerência de respostas entre eles. É importante salientar que não houve categorias com depoimentos antagônicos. No que diz respeito à triangulação de métodos, observou-se que nem sempre houve correspondência nos resultados quantitativos e qualitativos. Em relação à certificação, por exemplo, a ausência da mesma no período avaliado foi apontada nas duas abordagens metodológicas, bem como a importância do Projeto, em que as respostas quanti e qualitativas foram bastante coerentes. Contudo, no que diz respeito à inclusão social, os resultados quanti e qualitativos foram díspares. Enquanto a pesquisa qualitativa aponta para resultados do Projeto em termos de inclusão social, os resultados do quase-experimento apontam que o grupo controle teve médias mais altas de favorabilidade à inclusão social do que o grupo de tratamento. Por outro lado, a aceitação da inclusão escolar das pessoas com deficiência foi maior no grupo de tratamento do que no grupo controle.

Uma questão que a avaliação do Projeto levanta refere-se ao fato de que o discurso acerca da inclusão social é predominante na sociedade atual (como evidenciam as médias da escala de inclusão social que foram elevadas tanto para o grupo controle como para o grupo experimental). Porém, quando essa inclusão diz respeito a espaços onde as pessoas estão em convivência direta com os deficientes, nem sempre as posições de favorabilidade se mantêm. Um exemplo são os 
escores de inclusão escolar, em que o grupo de tratamento apresentou média mais elevada em relação à aceitação da inclusão escolar que o grupo controle.

Observa-se nas falas dos entrevistados que o Projeto contribui para o aprendizado sobre a cultura do Carnaval, para o desenvolvimento mental dos participantes, para a profissionalização e para a busca de novas formas de aprender a fazer as coisas. A relação com 0 Carnaval e o processo de inclusão a partir de um fenômeno cultural é um aspecto fortemente presente nos dados desta pesquisa. Neste sentido, alguns relatos dos pesquisados guardam consonância com a descrição que Barbieri (2009) faz do universo dos barracões e da complexidade da produção carnavalesca, com sua ampla rede de relações sociais na construção de uma arte coletiva. Além disso, o trabalho em torno do desfile é importante fator de valorização para as pessoas que se sentem parte integrante e ativa nas relações sociais cotidianas. A experiência de trabalho proporciona participação no processo produtivo, expansão dos relacionamentos, da condição econômica e das referências para a tomada de decisões (Lima \& J urdi, 2014; Volz et al., 2015).

Conforme estudo conduzido por Mazzotta e D'Antino (2011), em que se investiga a importância da mediação da cultura, da educação e do lazer no desenvolvimento sociocultural com foco no desenvolvimento pessoal e social, os autores chegaram à conclusão de que esses três componentes - a educação, a cultura e o lazer - são de fundamental importância para a inclusão da pessoa com deficiência, bem como de qualquer pessoa. Os elementos cultura e lazer são fortemente encontrados no Projeto avaliado, pois o mesmo prevê a inclusão a partir da participação das pessoas com deficiência no mundo da manifestação cultural carnavalesca. Contudo, o elemento educação fica restrito às oficinas realizadas ao longo do Projeto, uma vez que o mesmo não tem interação direta com as escolas nas quais os beneficiários estudam.

A participação da família no Projeto é um dos aspectos considerados como diferencial e que contribui para o alcance do objetivo geral. Esse resultado corrobora os achados de Leão e Barros (2008), que argumentam que os profissionais que atuam na área de saúde mental devem proporcionar iniciativas para estimular a realização de trocas sociais, principalmente dentro da rede social nuclear, que é a família. O Projeto avaliado claramente permite essas trocas na medida em que os familiares também participam das oficinas e desfiles.

A temática da diversidade individual também foi observada, ao abrir espaço para a presença de pessoas de diferentes tipos de necessidades, deficiências variadas e com diversidade cultural relevante. Assim, foi possível identificar falas do tipo "Muito interessante a forma como eles aprendem (...) dentro das suas possibilidades e condições", ou "temos que o público da Escola é 
extremamente variado, uma diversidade gigantesca, indo de 8 a 80 anos, sem distinção de classe social, ou credo religioso". Nesse sentido, pode-se considerar que o Projeto contribui para que a inclusão social ocorra em um espaço instituído, neste caso, a escola de samba. Esse é um aspecto que se aproxima da discussão apresentada por Mazzotta e D'Antino (2011), para quem a inclusão social ocorre em espaço instituído ou estruturado da vida social, quer seja na família, na escola, na empresa ou em qualquer forma de organização.

A vinculação do Projeto Embaixadores da Alegria com o objetivo de ampliar as chances de atuação dos beneficiários e familiares no mercado de trabalho do Carnaval, vai ao encontro de estudos que defendem a inclusão de pessoas com deficiência no mundo do trabalho como os realizados por Mourão, Sampaio e Duarte (2012), Carvalho-Freitas e Marques (2010), Lima e Jordi (2014) e Sassaki (2010). Não há dúvida que a inserção de pessoas com deficiência no mercado de trabalho é uma importante forma de inclusão social, pois a sociedade atual é fortemente pautada no mérito produtivo (Kubo \& Gouvea, 2012).

Outra importante categoria destacada nesta pesquisa foi a mobilidade, aqui entendida como a utilização de todos os equipamentos públicos disponíveis para locomoção para promover a acessibilidade das pessoas com deficiência na realização das suas atividades do dia a dia. A avaliação apontou a necessidade de mudança no local de realização para aumentar a acessibilidade das pessoas com deficiência, tendo em vista suas dificuldades de locomoção. Essa questão é aspecto central em programas e projetos que têm esse público como alvo, conforme discutido por Girondi e Santos (2011), que ressaltam que a mobilidade abrange questões como acessibilidade de transporte, de informação, de comunicação dentre outras. No que diz respeito à temática central do Projeto avaliado - inclusão social - vários autores reafirmam a necessidade de ampliar os estudos da área (Carvalho-Freitas \& Marques, 2010; Girondi \& Santos, 2011; Omote, Oliveira, Baleotti \& Martins, 2005; Mourão et al., 2012).

À guisa de conclusão, retomamos o objetivo da presente pesquisa de avaliar o Projeto Embaixadores da Alegria que visa promover a inclusão social das pessoas com quaisquer tipos de deficiência, utilizando como ferramenta a arte e a cultura do Carnaval. Os principais pontos de melhoria sugeridos são: (i) maior envolvimento da comunidade na qual os beneficiários estão inseridos, para ampliar a favorabilidade à inclusão social; (ii) ampliação da capacidade de atendimento do Projeto ou adequaçãoda meta de número de beneficiários à capacidade atual; (iii) revisão do desenho do Projeto no sentido de atender a algumas solicitações dos beneficiários; e (iv) sensibilização das autoridades públicas para aspectos como inclusão 
escolar, familiar e comunitária com planejamento urbanístico que atenda às necessidades desse público.

Como contribuições para os estudos da área, podem ser citadas: (i) a utilização do Inventário Geral de Atitudes em Relação à Educação Inclusiva, instrumento relevante para a pesquisa dessa temática, mas que ainda carece de estudos de evidência de validade para aprimorar sua consistência e indicadores psicométricos; (ii) a criação de uma escala de favorabilidade à inclusão social, dada a carência de medidas nessa temática;(iii) a realização de uma avaliação de projetos com base em um marco lógico e em um estudo multimétodo e com múltiplas fontes de pesquisa, considerando a demanda da área de maior rigor metodológico nas avaliações de programas sociais; e (iv) a avaliação de um programa que utiliza o Carnaval como ferramenta de inclusão social, uma vez que este importante recurso cultural brasileiro carece de mais pesquisas e, quiçá, de um uso social mais consistente.

Quanto às limitações desta pesquisa, podem ser citadas: (i) a dificuldade de realização de um experimento, tendo sido necessária a opção pelo quase-experimento; (ii) a dificuldade de alguns beneficiários em responder ao questionário de pesquisa; (iii) a realização de um estudo de corte transversal - quando se sabe que para mensuração de impacto, o ideal seria um estudo longitudinal; e (iv) a fragilidade da medida de inclusão escolar, pois não foram encontradas medidas mais adequadas para utilização.

Como sugestão de trabalhos futuros, muitos outros estudos poderiam ser enumerados tendo em vista a carência de pesquisas a respeito da inclusão social. Entre essas sugestões estão: aprofundar o estudo da contribuição da participação familiar como diferencial em projetos dessa natureza; investigar a possível contribuição da formação e das atitudes dos profissionais que trabalham em projetos sociais na efetividade dos mesmos; e estudar o desenvolvimento de uma escala de inclusão social de amplo espectro que possibilite a utilização nas pesquisas avaliativas dos diversos projetos e programas sobre essa temática.

\section{Referências}

Almeida, V. P. (2006). Avaliação de programas sociais: de mensuração de resultados para uma abordagem construtivista. Pesquisas e Práticas Psicossociais, 1(2), 1-13.

Barbosa, A. J. G., Rosini, D. C. \& Pereira, A. A. (2007). Inventário geral de atitudes em relação à educação inclusiva: análise das propriedades psicométricas. IV Congresso Brasileiro Multidisciplinar de Educação Especial. Londrina/PR.

Barbieri, R. J. (2009). Cidade do Samba: do barracão da escola às 
fábricas de carnaval. In M. L. Cavalcanti,\& R. Gonçalves. (Org.),Carnaval em Múltiplos Planos (pp. 125-145). Rio de Janeiro: Aeroplano Editora.

Bardin, L. (1977). Análise de Conteúdo. Lisboa: Edições 70.

Barros, A. S. S. (2015). Quarenta anos retratando a deficiência enquadres e enfoques da literatura infantojuvenil brasileira. Revista Brasileira de Educação, 20(60), 167-193.

Bauer, M. W. (2010). Análise de conteúdo clássica: uma revisão. In M. W. Bauer,\& G. Gaskell. Pesquisa Qualitativa com Texto: Imagem e Som: Um Manual Prático (pp. 189-217). Petrópolis: Vozes.

Carvalho-Freitas, M. N. \& Marques, A. L. (2010). Formas de ver as pessoas com deficiência: um estudo empírico do constructo de concepções de deficiência em situações de trabalho. Revista de Administração Mackenzie, 11(3), 100-128.

Estatuto da Pessoa com Deficiência (2015). Lei № 13.146, de 6 de julho de 2015. Institui a Lei Brasileira de Inclusão da Pessoa com Deficiência.

Fernandez-Ballesteros, R; Vedung, E.; Seyfried, E. (1998). Psychology in Program Evaluation. European Psychologist, 3, 143-154.

Furtado. J. P. (2001). Um método construtivista para avaliação em saúde. Ciência e Saúde Coletiva, 6(1), 165-181.

Girondi, J. B. R. \& Santos, S. M. A. (2011). Deficiência física em idosos e acessibilidade na atenção básica em saúde: revisão integrativa da literatura. Revista Gaúcha de Enfermagem, 32(2), 378-384.

Hair, J. F., Black, W. C., Babin, B. J., Anderson, R.E., \& Taham, R. L. (2009). Análise multivariada de dados (6 ed.). Porto Alegre: Bookman.

I pea - Instituto de Pesquisa Econômica Aplicada (2002). A iniciativa privada e o espírito público: Um retrato da ação social das empresas no Brasil. Brasília: PASE - Pesquisa Ação Social das Empresas.

Ipea - Instituto de Pesquisa Econômica Aplicada (2006). A iniciativa privada e o espírito público: A evolução da ação social das empresas privadas no Brasil. Brasília: PASE - Pesquisa Ação Social das Empresas.

Kubo, S. H., \& Gouvea, M. A. (2012). Análise de fatores associados ao significado do trabalho. Revista de Administração (São Paulo), 47(4), 540-554.

Leão, A. \& Barros. S. (2008). As representações sociais dos profissionais de saúde mental acerca do modelo de atenção e as possibilidades de inclusão social. Revista Saúde e Sociedade, 17(1), 95-106.

Lima, L. B. \& Jurdi, A. P. S. (2014). Empregabilidade de Pessoas com 
Deficiência no Município de Santos/SP: Mapeamento de Políticas Públicas e Práticas Institucionais. Revista Brasileira de Educação Especial, 20(4), 513-524.

MEC - Ministério da Educação (2008). Política Nacional de Educação Especial na Perspectiva da Educação Inclusiva.

Martins, G. A. (2008). Estudo de caso: Uma reflexão sobre a aplicabilidade em pesquisas no Brasil. Revista de Contabilidade e Organizações, 2(2), 8-18.

Mazzotta, M. J. S. \& D'Antino, M. E. F. (2011). Inclusão social de pessoas com deficiências e necessidades especiais: cultura, educação e lazer. Saúde e Sociedade, 20(2), 377-389.

Mourão, L., \& Laros, J. A. (2008). Avaliação de programas sociais: Comparando estratégias de análise de dados. Psicologia: Teoria e Pesquisa 24(4), 545-558.

Mourão, L. \& Meneses, P. P. M. (2012). Medidas de avaliação em treinamento, desenvolvimento e educação: ferramentas para gestão de pessoas. Porto Alegre: Artmed.

Mourão, L., Sampaio, S., \& Duarte, M. H. (2012). Colocação seletiva de pessoas com deficiência intelectual nas organizações: um estudo qualitativo. Organização e Sociedade, 19(61), 209-229.

Murta, S. G., Laros, J. A., \& Tróccoli, B. T. (2005). Manejo de estresse ocupacional na perspectiva da área de avaliação de programas. Estudos de Psicologia (Natal), 10(2), 167-176.

Omote, S., Oliveira, A. A. S., Baleotti, L. R. \& Martins, S. E. S. (2005). Mudança de atitudes sociais em relação à inclusão. Revista Paidéia, 15(32), 387-398.

Peliano, A. M. T. M. (Org.) (2009). Cultivando os frutos sociais: a importância da avaliação nas ações das empresas. Brasília: IPEA.

Projeto Embaixadores da Alegria (2009). Plano de trabalho. Rio de Janeiro: Escola Embaixadores da Alegria.

Sassaki, R. K. (2010). Inclusão: Construindo uma sociedade para todos. Rio de Janeiro: WVA Editora.

Yin, R. K. (2009). Case study research: Design and methods. New York: Sage Publications Inc.

Tabachinick, B. G., \& Fidell, L. S. (2007). Using multivariate statistics. New York: HarperCollins.

Volz, P. M. Tomasi, E., Bruck, N. R. V., Saes, M. O., Nunes, B. P., Duro, S. M. S., Facchini, L. A. (2015). A inclusão social pelo trabalho no processo de minimização do estigma social pela doença. Saúde e Sociedade, 24(3), 877-886.

Worthen, B., Sanders, J., \& Fitzpatrick, J. (2004). Avaliação de programas: concepções e práticas. São Paulo: EDUSP. 


\section{Endereço para correspondência}

J ussélio Rodrigues Ribeiro

Universidade Salgado de Oliveira

Rua Marechal Deodoro, 217 - 2o andar, Centro, CEP 24030-060, Niterói - RJ, Brasil Endereço eletrônico: jusselio.2011@gmail.com

\section{Luciana Mourão}

Universidade Salgado de Oliveira

Rua Marechal Deodoro, 217 - 2o andar, Centro, CEP 24030-060, Niterói - RJ, Brasil

Endereço eletrônico: mourao.luciana@gmail.com

Recebido em: 14/07/2016

Reformulado em: 28/07/2016

Aceito para publicação em: 25/09/2016

\section{Notas}

* Mestre em Psicologia Social, Especialista em Tecnologia da Informação, Gestão de Negócios e de Projetos, Especialista em Gestão Empresarial e graduado em Administração de Empresas. Atualmente trabalha em Furnas Centrais Elétricas S/A (2006) e professor das Faculdades Integradas de Aracruz (FAACZ).

** Doutora em Psicologia, Mestre em Administração, Graduação em Comunicação Social e Administração. Professora do Programa de Pós-Graduação em Psicologia da Universidade Salgado de Oliveira e da Associação Internacional de Educação Continuada. Pesquisadora do CNPq. 